\title{
Oligonol, a low-molecular-weight polyphenol derived from lychee fruit, attenuates gluco-lipotoxicity-mediated renal disorder in type 2 diabetic $d b / d b$ mice
}

\author{
Chan Hum Park ${ }^{1}$, Jeong Sook Noh ${ }^{2}$, Hajime Fujii ${ }^{3}$, Seong-Soo Roh ${ }^{1}$, Yeong-Ok Song ${ }^{4}$, Jae Sue Choi ${ }^{5}$, \\ Hae Young Chung ${ }^{6}$, Takako Yokozawa, ${ }^{1,6,7, *}$
}

${ }^{1}$ College of Korean Medicine, Daegu Haany University, Daegu, Korea;

${ }^{2}$ Department of Food Science \& Nutrition, Tongmyong University, Busan, Korea;

${ }^{3}$ Amino Up Chemical Company, Ltd., Sapporo, Japan;

${ }^{4}$ Department of Food Science Nutrition, Pusan National University, Busan, Korea;

${ }^{5}$ Division of Food Science \& Biotechnology, Pukyong National University, Busan, Korea;

${ }^{6}$ Molecular Inflammation Research Center for Aging Intervention, Pusan National University, Busan, Korea;

${ }^{7}$ Graduate School of Science and Engineering for Research, University of Toyama, Toyama, Japan.

\begin{abstract}
Summary Oligonol is a phenolic product derived from lychee fruit extract containing catechin-type monomers and oligomers of proanthocyanidins, produced by a manufacturing process which converts polyphenol polymers into oligomers. These proanthocyanidins have been reported to exhibit beneficial bioactivities in many studies, and so oligonol, a rich source of polyphenol, is expected to show favorable effects on various chronic diseases. This article summarizes recent work whether oligonol has an ameliorative effect on diabetic indices and renal disorders associated with gluco-lipotoxicity-mediated oxidative stress, inflammation, and apoptosis in $d b / d b$ mice with diabetes. Oligonol was able to improve diabetic indices, prevent the development of diabetic renal disease, and preserve renal cells and the renal morphological structure via the attenuation of reduced nicotinamide adenine dinucleotide phosphate (NADPH) oxidase-induced oxidative stress, inhibition of advanced glycation endproduct (AGE) generation, and prevention of apoptosis-induced cell death in $d b / d b$ mice, being independent of changes in the body weight or serum glucose levels. The present study provides important evidence that oligonol exhibits a pleiotropic effect, representing renoprotective effects against the development of diabetic complications in type 2 diabetic $d b / d b$ mice.
\end{abstract}

Keywords: Oligonol, type 2 diabetes, renoprotective effects

\section{Introduction}

The major biochemical alterations in diabetes are hyperglycemia and dyslipidemia, leading to gluco- and lipotoxicity, respectively, which directly or indirectly account for diabetic complications in various organs such as nonalcoholic fatty liver disease, chronic kidney disease, pancreatic $\beta$-cell apoptosis, and diabetic

\footnotetext{
*Address correspondence to:

Dr. Takako Yokozawa, Graduate School of Science and Engineering for Research, University of Toyama, 3190 Gofuku, Toyama 930-8555, Japan.

E-mail: yokozawa@inm.u-toyama.ac.jp
}

cardiomyopathy (1-4).

Hyperglycemia causes oxidative stress by two mechanisms: firstly, by decreasing the regeneration of the important cellular antioxidant, reduced glutathione (GSH) from oxidized glutathione (GSSG), and, secondly, by decreasing the availability of reduced nicotinamide adenine dinucleotide phosphate (NADPH) (5). Furthermore, hyperglycemia-induced reactive oxygen species (ROS) stimulate the activation of protein kinase $\mathrm{C}$ (PKC), formation of advanced glycation endproducts (AGEs), and sorbitol accumulation. Also, an increase in ROS leads to the activation of nuclear factor-kappa $\mathrm{B}(\mathrm{NF}-\kappa \mathrm{B})$, and activated $\mathrm{NF}-\kappa \mathrm{B}$ can enhance the expression of proinflammatory cytokines, chemokines, 
adhesion molecules, inflammatory receptors, and inflammatory enzymes such as inducible nitric oxide synthase (iNOS) and cyclooxygenase-2 (COX-2) (6-8).

Long-term hyperlipidemia, which is associated with the abnormal expression of transcriptional factors such as peroxisome proliferator-activated receptor (PPAR) $\alpha$ or sterol regulatory element-binding protein (SREBP) in the nucleus, increases non-esterified fatty acid (NEFA) uptake and accumulations of triglycerides and cholesterol in tissues such as the liver and kidney. In addition, critical toxicity caused by dyslipidemia is due to oxidative and carbonyl stress as a result of impaired antioxidant defense systems and increased ROS generated by the mitochondrial respiratory chain reaction, nonenzymatic glycation, and glucose autoxidation (9-12).

There have been many studies to identify effective therapeutic agents from natural sources for metabolic disorders such as obesity, diabetes mellitus, and its complications due to their absence of toxic and/or side effects (13). Currently, functional food and/or dietary ingredients with health benefits are given much attention due to the absence of adverse effects, abundant production, and application to various commercial products (14). Polyphenol-rich foods, such as wine, tea, coffee, and chocolate, have been receiving considerable attention as dietary sources of antioxidants that are valuable for human health. Polyphenols, including catechins and their derivatives, resveratrol, and curcumin, have attracted attention as functional foods with various bioactivities, such as anticancer, antimutagenic, antimicrobial, and antiviral activities (15-17).

The lychee (Litchi chinensis, Sapindaceae) has been consumed since ancient times in China and the southern area of Southeast Asia. The lychee is rich in polyphenols; Brat et al. (18) reported that its polyphenol content per edible part is second only to strawberries. A particular feature of lychee polyphenols is a phenolic product containing catechin-type monomers and oligomers of proanthocyanidins. Proanthocyanidins are structurally characterized as polymers of catechin and have a high molecular weight. However, their absorption in the body is low when administered orally, and so their in vivo activity is not as high as expected. Moreover, proanthocyanidins with a high molecular weight are practically insoluble in water and have an astringent taste, binding to salivary proteins and mucous membranes in the mouth (19), and making them difficult to use in the food industry. Tanaka et al. (20) were successful in converting high-molecular-weight proanthocyanidin into low-molecular-weight proanthocyanidin, which is utilizable in the food industry. Therefore, in this review, we summarize recent work on the effects of oligonol on diabetic indices and renal disorders associated with gluco-lipotoxicity-mediated oxidative stress, inflammation, and apoptosis in $d b / d b$ mice with diabetes.

\section{Conversion to low-molecular-weight proanthocyanidin}

For a prolonged period, a thiolysis method has been used for the structural analysis of proanthocyanidin. In this method, based on a nucleophilic reaction, a compound possessing a thiol group binds to the end unit of proanthocyanidin fragmented under acidic conditions, and, accordingly, low-molecular-weight proanthocyanidin is stably obtained. However, as most compounds with a thiol group are not suitable for consumption, their application to food products is limited. Tanaka et al. (20) developed a technique to convert high-molecular-weight proanthocyanidins to low-molecular-weight proanthocyanidins without using thiol compounds, and have been successful in making the technology practicable. This method involves binding a compound possessing a phloroglucinol ring structure (such as catechin) as a nucleophilic compound to proanthocyanidin fragmented under acidic conditions. As shown in Figure 1, catechin

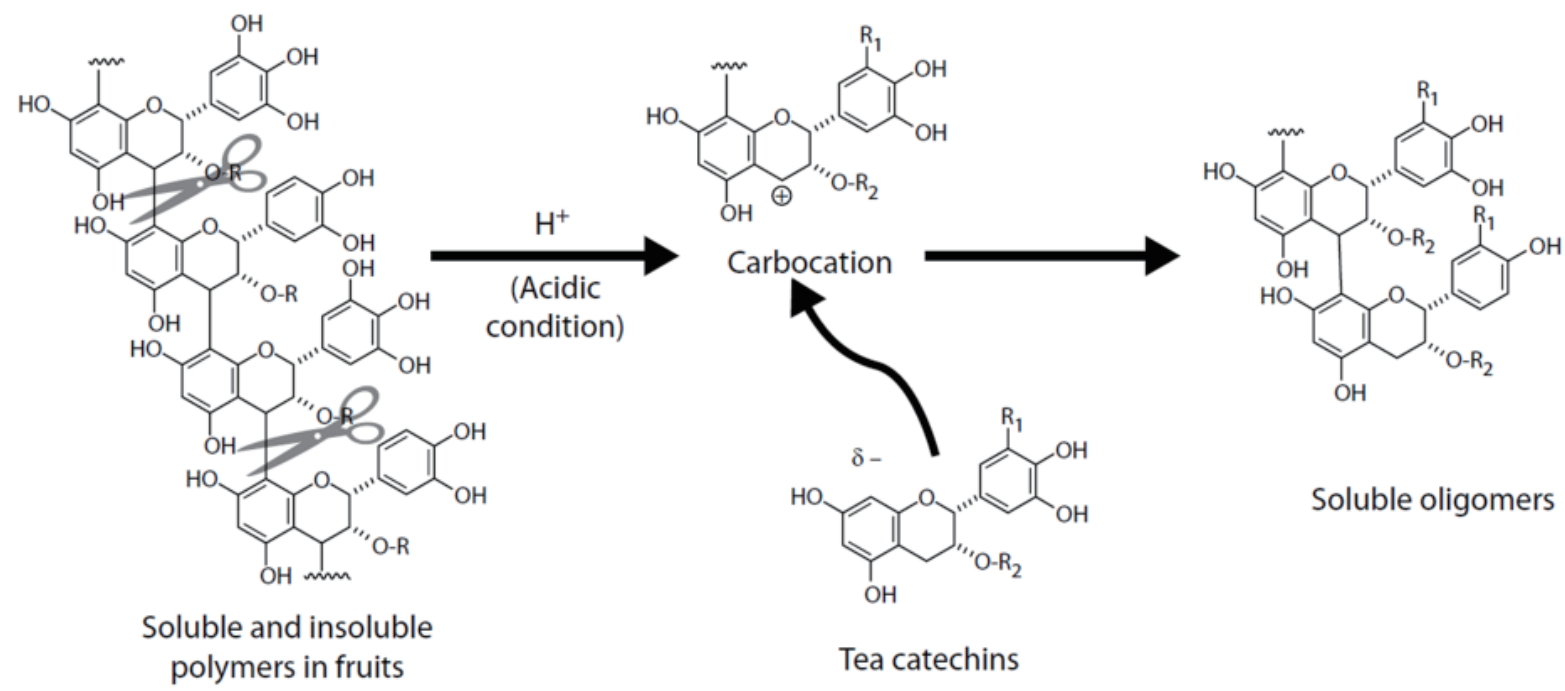

Figure 1. A conceptual diagram showing the conversion of proanthocyanidin to a low molecular weight. Ref. (20). 
monomers are substituted at the C-4 position of fragmented proanthocyanidins with a high molecular weight and, as a consequence, low-molecular-weight proanthocyanidins are stably generated.

\section{Oligonol}

Oligonol is produced by oligomerizing polyphenol polymers derived from lychee fruit, as described previously (21). Briefly, dried lychee fruits, one of the richest sources of polyphenols, are extracted with 50\% $(\mathrm{v} / \mathrm{v})$ ethanol. The filtrate is evaporated and passed through a DIAION HP-20 column, and eluted with ethanol. The eluate is evaporated to dryness, yielding a dark brown powder which contains a mixture of proanthocyanidins. The lychee extract is mixed with green tea extract, which provides an enriched source of monomeric procyanidins, and citric acid in water. The reaction mixture is heated at $60^{\circ} \mathrm{C}$ for $16 \mathrm{~h}$, filtered through a DIAION HP-20 column, washed with water, and eluted with $40 \%(\mathrm{v} / \mathrm{v})$ ethanol. Evaporation of the eluate yields a reddish brown powder containing the monomeric and oligomeric proanthocyanidin mixture. Oligonol comprises a polyphenol mixture of $15.3 \%$ monomers (including catechin) and $16.7 \%$ dimers (including procyanidin and catechin), whereas lychee fruit polyphenol comprises a mixture of $6.4 \%$ monomers and $9.8 \%$ dimers (Table 1). Oligonol is commercially available (Amino Up Chemical Co., Ltd., Sapporo, Japan). The safety of oligonol as a food or dietary supplement and as a pharmaceutical additive has already been confirmed $(21,22)$.

\section{Function of oligonol against diabetes-induced renal damage in $d b / d b$ mice}

There is accumulating evidence that oligonol can exert some biological effects in vitro and in vivo: anticancer

Table 1. Contents of oligonol and lychee fruit polyphenol

\begin{tabular}{lcc}
\hline Items & Oligonol & $\begin{array}{c}\text { Lychee fruit } \\
\text { polyphenol }\end{array}$ \\
\hline Monomers & & \\
$\quad(+)-C a t e c h i n /(-)-E p i c a t e c h i n$ & $6.9 \%$ & $6.4 \%$ \\
(-)-Epicatechin gallate & $1.4 \%$ & n.d. \\
(-)-Epigallocatechin gallate & $7.0 \%$ & n.d. \\
& & \\
Dimers & & \\
Procyanidin A1 & $6.2 \%$ & $4.0 \%$ \\
Procyanidin A2 & $6.6 \%$ & $3.3 \%$ \\
Procyanidin B1 & $0.4 \%$ & $0.8 \%$ \\
Procyanidin B2 & $2.0 \%$ & $1.7 \%$ \\
Catechin-epigallocatechin gallate & $1.5 \%$ & n.d. \\
\hline
\end{tabular}

Oligonol comprises a polyphenol mixture of $15.3 \%$ monomers $((+)$-catechin, (-)-epicatechin, (-)-epicatechin gallate, and (-)-epigallocatechin gallate) and $16.7 \%$ dimers (procyanidin A1, A2, $\mathrm{B} 1, \mathrm{~B} 2$, and catechin-epigallocatechin gallate), while lychee fruit polyphenol comprises a mixture of $6.4 \%$ monomers and $9.8 \%$ dimers. Ref. (31).
(23) as well as antioxidant and anti-inflammatory effects (24), beneficial activity for nitric oxide bioavailability (25), and a regulatory effect on lipid metabolism $(26,27)$. Indeed, dietary feeding with proanthocyanidins, which comprise oligonol, has been reported to induce a significant attenuation of tissue fat levels, without changing the total body mass of the animals compared with non-proanthocyanidin-fed animals (28). Thus, many beneficial physiological activities of oligonol have been reported, and this review was focused that oligonol has ameliorative effects on the kidney in type 2 diabetes.

Diabetic kidney damage is one of the most serious complications of diabetes mellitus and has been the most common cause of end-stage renal failure among patients undergoing chronic hemodialysis therapy since 1998 (29). Therefore, we proposed the effects of oligonol on diabetic indices and renal damage in type 2 diabetic $d b / d b$ mice, as reported previously $(30,31)$.

\subsection{Diabetic indices and renal histological examination}

To investigate the effect of oligonol, $d b / d b$ mice were used. The spontaneous mutant strain C57BLKS/ $\mathrm{J} d b / d b$ mice have a $d b$ gene mutation, a splicing mutation caused by a point mutation in the downstream intron of the leptin receptor gene, and so they are unresponsive to leptin. Leptin is a peptide hormone secreted by adipocytes, and it is involved in eating behavior and energy homeostasis. For this reason, after birth, homozygous type 2 diabetic $(d b / d b)$ mice show unrepressed eating behavior, become obese, and develop severe insulin resistance associated with hyperinsulinemia and hyperglycemia (32). In this study, $d b / d b$ mice showed diabetic characteristics, such as excessive body weight gain, increased food and water intakes, hyperglycemia, hyperinsulinemia, and hyperleptinemia, compared with homozygous control $(\mathrm{m} / \mathrm{m})$ mice. However, oligonol administration did not affect the body weight gain or serum glucose and leptin concentrations in spite of elevated serum insulin. In oligonol-administered $d b / d b$ mice, the cause of increased insulin secretion is unclear and may be related to preservation of the pancreatic $\beta$-cell function by oligonol treatment. In addition, there were significant reductions in the serum lipid concentration (triglycerides, total cholesterol, and NEFA), ROS, and lipid peroxidation, as well as improvements in renal function parameters such as serum urea nitrogen and creatinine. Serum adiponectin concentrations were significantly higher in the oligonol-treated than in the vehicle $d b / d b$ group, as shown in Table 2 . Low adiponectin levels are associated with insulin resistance in type 2 diabetic patients and experimental animals (33). Unfortunately, we cannot measure the insulin sensitivity regarding the influence on target tissues such as muscle and fat. In addition to biofactors such 
Table 2. Hematological analyses

\begin{tabular}{lcccc}
\hline & \multirow{2}{*}{$m / m$} & \multicolumn{3}{c}{$d b / d b$} \\
\cline { 3 - 5 } Items & & Veh & O10 & O20 \\
\hline Glucose (mg/dL) & $153 \pm 12^{* * *}$ & $594 \pm 29$ & $571 \pm 61$ & $668 \pm 41$ \\
Insulin (ng/mL) & $0.17 \pm 0.08^{* * *}$ & $1.77 \pm 0.18$ & $1.71 \pm 0.22$ & $2.86 \pm 0.32^{* *}$ \\
Leptin (ng/mL) & $3.0 \pm 0.4^{* * *}$ & $19.8 \pm 0.3$ & $19.5 \pm 0.2$ & $19.3 \pm 0.4$ \\
Urea nitrogen (mg/dL) & $31.5 \pm 2.9^{* *}$ & $44.4 \pm 2.4$ & $40.4 \pm 2.4$ & $28.6 \pm 1.7^{* * *}$ \\
Creatinine (mg/dL) & $0.23 \pm 0.02^{*}$ & $0.35 \pm 0.04$ & $0.37 \pm 0.04$ & $0.26 \pm 0.02^{*}$ \\
Triglyceride (mg/dL) & $76 \pm 6^{* * *}$ & $220 \pm 18$ & $197 \pm 30$ & $161 \pm 20^{*}$ \\
Total cholesterol (mg/dL) & $76 \pm 4^{* * *}$ & $157 \pm 13$ & $139 \pm 8$ & $124 \pm 7^{*}$ \\
NEFA (mEq/L) & $0.74 \pm 0.10^{* * *}$ & $1.41 \pm 0.08$ & $1.18 \pm 0.13$ & $1.10 \pm 0.09^{*}$ \\
Adiponectin (ng/mL) & $6.12 \pm 0.62^{* * *}$ & $2.42 \pm 0.23$ & $2.93 \pm 0.20^{*}$ & $3.12 \pm 0.12^{*}$ \\
ROS (fluorescence/min/mL) & $171 \pm 27^{*}$ & $321 \pm 42$ & $214 \pm 24^{*}$ & $145 \pm 24^{* *}$ \\
TBARS (nmol/mL) & $5.7 \pm 0.2^{* * *}$ & $14.9 \pm 1.3$ & $13.4 \pm 1.1$ & $7.1 \pm 0.3^{* * *}$ \\
\hline
\end{tabular}

Values are mean \pm S.E.M. Significance: ${ }^{*} p<0.05,{ }^{* *} p<0.01,{ }^{* * *} p<0.001 v s$. vehicle-treated $d b / d b$ group. $m / m$, vehicle-treated $m / m$ mice $(n=6)$; $d b / d b$-Veh, vehicle-treated $d b / d b$ mice $(n=10) ; d b / d b$-O10, oligonol $10 \mathrm{mg} / \mathrm{kg}$ body weight-treated $d b / d b$ mice $(n=10)$; d $b / d b$-O20, oligonol 20 $\mathrm{mg} / \mathrm{kg}$ body weight-treated $d b / d b$ mice $(n=10)$. Ref. $(30)$.

(A)

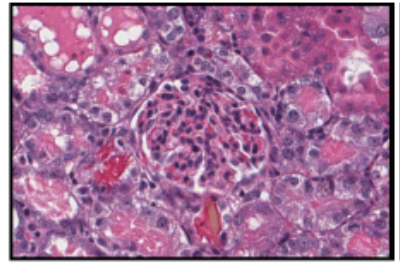

(B)

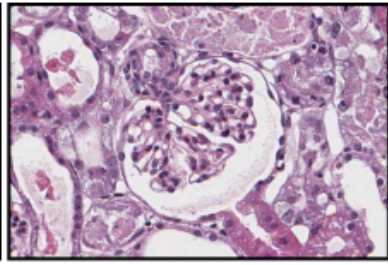

(C)

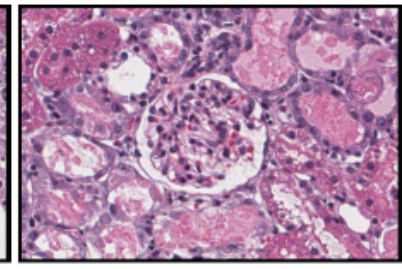

(D)

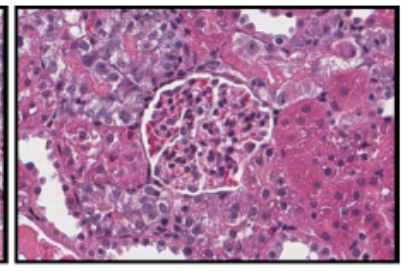

Figure 2. H/E staining of renal tissue. Vehicle-treated $\mathrm{m} / \mathrm{m}$ mice (A), vehicle-treated $\mathrm{db} / \mathrm{db}$ mice (B), oligonol $10 \mathrm{mg} / \mathrm{kg}$ body weight-treated $d b / d b$ mice (C), oligonol $20 \mathrm{mg} / \mathrm{kg}$ body weight-treated $d b / d b$ mice (D). Images are at 200x magnification. Ref. (31).

as the lipid profile and oxidative stress, kidney damage was controlled under type 2 diabetic conditions with oligonol administration. Figure 2 shows representative microphotographs of renal hematoxylin and eosin $(\mathrm{H} / \mathrm{E})$ staining. When compared with $\mathrm{m} / \mathrm{m}$ mice (Figure 2A), the marked glomerular enlargement observed in $d b /$ $d b$ mice (Figure 2B) was clearly improved on oligonol treatment (Figures $2 \mathrm{C}$ and 2D). These results indicate that oligonol protects against renal injury induced in type 2 diabetic $d b / d b$ mice.

To investigate the effects of oligonol on renal damage induced by hyperglycemia and abnormal lipid synthesis, the influence of hyperglycemia and hyperlipidemia in the kidneys of $d b / d b$ mice was also examined. The renal contents of triglycerides and total cholesterol were significantly decreased by the administration of oligonol. These results indicate that the biological activities of oligonol in the serum of $d b /$ $d b$ mice are associated with lipid metabolism, such as synthesis or deposition for energy production.

Lipid homeostasis is regulated by a family of membrane-bound transcription factors called SREBPs. Up-regulations of SREBP-1 and SREBP-2 were reported in leptin-resistant mice such as $o b / o b$ and $\mathrm{FVB}^{d b / d b}$ mice $(34,35)$. In our study, the increase in renal SREBP-1 and SREBP-2 in $d b / d b$ mice was downregulated by the administration of oligonol. This was probably related to the inhibition of renal triglyceride and total cholesterol accumulation. Furthermore, PPARs, with three isoforms $(\alpha, \delta$, and $\gamma)$, are also involved in the long-term regulation of lipid metabolism, and their activity is modulated by endogenous lipid-derived ligands. When PPAR $\alpha$ is activated, it promotes fatty acid oxidation, ketone body synthesis, and glucosesparing (36) and ameliorates diabetes, insulin resistance, albuminuria, glomerular hypertrophy, and mesangial expansion in $d b / d b$ mice (37). The decreased renal PPAR $\alpha$ level in $d b / d b$ mice was significantly increased on oligonol administration. These results clarify the effect of oligonol on regulations of both PPAR $\alpha$ and SREBP protein expressions.

\subsection{Oligonol attenuates diabetes-induced renal damage triggered by ROS-related pathway}

Hyperglycemia and elevated NEFA levels result in the generation of ROS, and, consequently, increase oxidative stress. ROS not only directly damage cells by oxidizing DNA, proteins, and lipids, but also indirectly damage them by activating a variety of stress-sensitive intracellular signaling pathways such as NF- $\kappa \mathrm{B}, \mathrm{p} 38$ mitogen-activated protein kinase (MAPK), $\mathrm{NH}_{2}$-terminal Jun kinase/stress-activated protein kinase, hexosamines, $\mathrm{PKC}$, and $\mathrm{AGE} /$ receptor for AGE (RAGE). Activation of these pathways results in the increased expression of numerous gene products that cause cellular damage and play a major role in the etiology of later-stage complications of 
Table 3. Biomarkers associated with oxidative stress in the kidney

\begin{tabular}{|c|c|c|c|c|}
\hline \multirow{2}{*}{ Items } & \multirow{2}{*}{$m / m$} & \multicolumn{3}{|c|}{$d b / d b$} \\
\hline & & Veh & $\mathrm{O} 10$ & $\mathrm{O} 20$ \\
\hline ROS (fluorescence/min/mg protein) & $1057 \pm 94^{* *}$ & $3069 \pm 327$ & $1970 \pm 282^{*}$ & $764 \pm 112^{* * *}$ \\
\hline TBARS (nmol/mg protein) & $1.11 \pm 0.05^{* *}$ & $1.51 \pm 0.07$ & $1.37 \pm 0.05$ & $1.18 \pm 0.09^{*}$ \\
\hline $\mathrm{GSH}(\mu \mathrm{mol} / \mathrm{mg}$ protein $)$ & $3.02 \pm 0.18$ & $2.95 \pm 0.09$ & $3.23 \pm 0.33$ & $3.08 \pm 0.17$ \\
\hline GSSG ( $\mu \mathrm{mol} / \mathrm{mg}$ protein $)$ & $1.40 \pm 0.03^{* *}$ & $1.63 \pm 0.04$ & $1.47 \pm 0.05^{*}$ & $1.52 \pm 0.06$ \\
\hline GSH/GSSG ratio & $2.17 \pm 0.13^{*}$ & $1.80 \pm 0.04$ & $2.19 \pm 0.18$ & $2.05 \pm 0.15$ \\
\hline
\end{tabular}

Values are mean \pm S.E.M. Significance: ${ }^{*} p<0.05,{ }^{* *} p<0.01,{ }^{* * *} p<0.001 v s$. vehicle-treated $d b / d b$ group. $m / m$, vehicle-treated $m / m$ mice $(n=6)$; $d b / d b$-Veh, vehicle-treated $d b / d b$ mice $(n=10) ; d b / d b$-O10, oligonol $10 \mathrm{mg} / \mathrm{kg}$ body weight-treated $d b / d b \mathrm{mice}(n=10) ; \mathrm{d} b / d b-\mathrm{O} 20$, oligonol 20 $\mathrm{mg} / \mathrm{kg}$ body weight-treated $d b / d b$ mice $(n=10)$. Ref. $(30)$.

diabetes (38). Thus, the up-regulation of endogenous antioxidative systems and suppression of oxidative stress are important factors ameliorating diabetes and its complications.

We investigated ROS generation and lipid peroxidation, as biomarkers associated with oxidative stress, and also measured GSH and GSSG as indicators of an endogenous antioxidative system. Lipid peroxidation leads to oxidant production from many molecules, and, thus, amplifies oxidative damage (39). Our results showed that the level of ROS generation and that of lipid peroxidation in the serum and kidney were increased in $d b / d b$ mice, which suggests that these mice show increased oxidative damage due to an elevation of ROS generation induced by hyperglycemia and hyperlipidemia. However, oligonol treatment exerted antioxidant activity, promoting decreased serum ROS and 2-thiobarbituric acid-reactive substance (TBARS) levels with corresponding effects on renal tissue in $d b / d b$ mice (Tables 2 and 3). Regarding GSH/GSSG ratios, the $d b / d b$ vehicle group showed a significant reduction compared with the $m / m$ group, which resulted from the marked increase in the GSSG concentration in the kidney. However, oligonol treatment did not significantly alter the renal GSH level and GSH/GSSG ratio (Table 3). This suggests that the administration of oligonol would ameliorate oxidative stress under type 2 diabetes through the inhibition of ROS generation and lipid peroxidation, and, thus, it would result in the improvement of renal disorders caused by oxidative stress.

Many researchers have demonstrated that catechin and its derivatives exhibited a favorable antioxidative effect and attenuated oxidative stress under diverse, chronic, degenerative conditions (40). Furthermore, there is increasing evidence of the potential benefits of polyphenols containing catechin in the regulation of cellular processes such as redox control and the inflammatory response based on established animal models and clinical studies $(41,42)$. Recently, our studies have shown that epigallocatechin gallate ameliorates glucose toxicity and renal injury, thereby alleviating renal damage caused by abnormal glucose metabolism-associated oxidative stress in diabetic nephropathy (43). Since oligonol contained catechin-
(A)
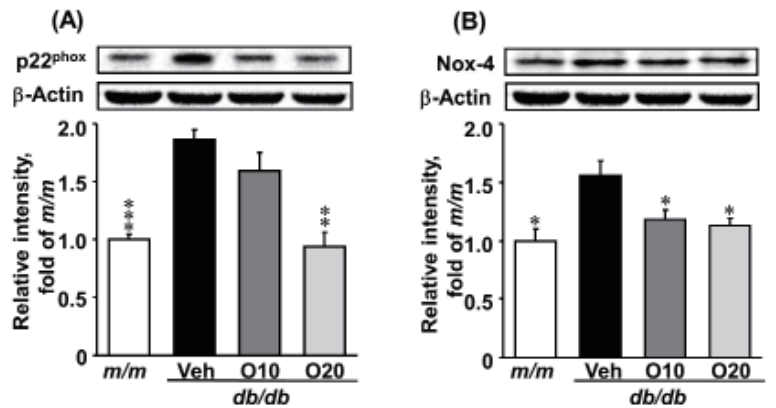

Figure 3. Renal p22 $2^{\text {phox }}$ (A) and Nox-4 (B) protein expressions. Values are mean \pm S.E.M. Significance: ${ }^{*} p<0.05$, ${ }^{* *} p<0.01,{ }^{* * *} p<0.001 \mathrm{vs}$. vehicle-treated $\mathrm{db} / \mathrm{db}$ group. $\mathrm{m} / \mathrm{m}$, vehicle-treated $m / m$ mice $(n=6) ; d b / d b$-Veh, vehicle-treated $d b / d b$ mice $(n=10) ; d b / d b-O 10$, oligonol $10 \mathrm{mg} / \mathrm{kg}$ body weight-treated $d b / d b$ mice $(n=10) ; d b / d b-\mathrm{O} 20$, oligonol 20 $\mathrm{mg} / \mathrm{kg}$ body weight-treated $d b / d b$ mice $(n=10)$. Ref. (31).

based oligomers, we assumed that it could attenuate oxidative stress induced by chronic hyperglycemia and/ or direct NADPH oxidase-dependent ROS generation in type 2 diabetes. In the kidney cortex of $d b / d b$ mice, protein expressions of NADPH oxidase-4 (Nox-4) (NADPH oxidase homologs) and $\mathrm{p} 22^{\text {phox }} / \mathrm{p} 47^{\text {phox }}$ (subunit of NADPH oxidase) were increased, and Nox-4 was a major source of renal ROS through the p38 MAPKdependent pathway (44). Our study demonstrated that oligonol decreased the renal ROS concentration as well as down-regulated the expression of NADPH oxidase, as shown in Table 3 and Figure 3. These results suggest that the attenuation of oxidative stress in renal tissue by oligonol is associated with the reduction of NADPH oxidase activity.

\subsection{Oligonol acts as a regulator of diabetes-induced renal damage through an AGE-related pathway}

AGEs are elevated under chronic hyperglycemia and excessive glucose uptake in tissues, and, furthermore, their formation can be accelerated by increased oxidative stress (45). Some polyphenols, including green tea catechins and epicatechins, chlorogenic acids, quercetin, and naringenin, could inhibit the absorption of glucose from the intestine via the inhibition of sodium-dependent glucose transporter (SGLT) 1 and SGLT2 (40). Glucose transporter isoform 2 (GLUT2)- 
mediated glucose transport was inhibited by apigenin, quercetin, myricetin, and tea catechins $(47,48)$. Polyphenol also shows a wide range of target tissue and is distributed in various organs, including the liver and kidney. Our study shows that the increased glucose concentration in the kidney of $d b / d b$ mice is decreased by oligonol treatment. Thus, the decreased renal glucose concentration may be due to SGLT1, SGLT2, and GLUT2 inhibition.

AGEs are complex compounds formed via a nonenzymatic reaction between reducing sugars and amine residues on proteins, lipids, or nucleic acids (49). The intracellular production and accumulation of AGEs are closely linked to diabetic complications such as neuropathy, retinopathy, and nephropathy $(50,51)$. Especially, there is a strong correlation between AGE accumulation and the duration and degree of severity of diabetic kidney disease (52). AGEs can interact with certain receptors, such as RAGE, to induce intracellular signaling, which leads to enhanced oxidative stress and the production of key proinflammatory and prosclerotic cytokines. Recently, attention has been focused on the essential roles of AGEs, that is, AGEs alter the structure and function of matrix tissue proteins, and AGE-modified proteins stimulate a variety of cellular responses via a specific cell surface receptor, resulting in the expression and activation of pathogenic mediators, e.g., the extracellular matrix, oxidative stress, cytokines, and growth factors, implicated in the development and stimulation of diabetic renal diseases (53). We evaluated the protein expressions of AGEs and receptors, such as pentosidine, $N^{e}$ (carboxymethyl)arginine (CMA), glycolaldehyde (GA)-pyridine, $N^{\varepsilon}$-(carboxymethyl)lysine (CML), $N^{e}$-(carboxyethyl)lysine (CEL), and RAGE, in the kidney. These products are not only derived from intermediates of glucose metabolism and metabolites of glycolysis, but also serve as general bio-markers of oxidative stress resulting from carbohydrate and lipid oxidation reactions (54). Pentosidine, a cross-link between arginine and lysine, is a well-characterized AGE (55). Recently, serum pentosidine concentrations were shown to be closely associated with peripheral arterial disease in type 2 diabetes mellitus patients (56). Odani et al. (57) suggested that CMA was a new marker of diabetic complications, and that its serum concentration was increased in diabetic patients with non-renal failure compared with a healthy control group. CMA production increased in parallel with the incubation time, and its yield was greater than that of pentosidine (58). GA was formed either as a fragmentation product in the Maillard reaction or as a result of the myeloperoxidase-hydrogen peroxidechloride reaction $(59,60)$. GA-pyridine, a specific GAderived AGE, has been described in foam cells and in the extracellular matrix of human atherosclerotic fibrotic lesions, and also reported to show mesangial accumulation in human renal disease (61). The hydroxy-amino acid L-serine is oxidized and converted to reactive carbonyl compounds, such as GA which is highly reactive with proteins, leading to the formation of CML (60). Taking the above-mentioned studies together, AGE formation, accumulation, and interaction with RAGE were increased and aggravated under the diabetic condition, consistent with our findings such as the up-regulated expression of these proteins in the kidney of type 2 diabetic mice. However, oligonol administration effectively down-regulated AGE-related protein expressions (RAGE, CMA, GA-pyridine, CML, and CEL) (Figure 4). These results suggest that the inhibitory activity of oligonol on AGE formation and its receptor expressions shows clinical potential, including its delay of AGE-related disorder development in diabetes. The reno-protective effects of oligonol against diabetes were not attributable to improved renal glycemic adjustment alone, but also likely reflected its antioxidant activity. The combined antioxidant and reduction of the glycation reaction by oligonol should be particularly advantageous and perhaps even synergistic in preventing renal injury and other diabetic complications.

\subsection{Oligonol attenuates diabetes-induced renal damage by ROS-sensitive pathway of inflammation and apoptosis}

A possible pathway of ROS-associated apoptosis was suggested by the observation that increased oxidative stress activates c-Jun N-terminal kinase (JNK) and p38 MAPK through apoptosis signal-regulating kinase 1 (62). JNK activation has been suggested to be involved in the regulation of tumor necrosis factor- $\alpha$ (TNF- $\alpha$ )induced c-Jun kinase and apoptosis (63). Otherwise, the suppression of JNK and p38 MAPK mediated antiapoptotic signaling (64). We evaluated the expression of pro-apoptotic cellular signal-related protein in diabetic renal tissues. The renal protein expressions of JNK, phosphor-JNK (p-JNK), c-Jun, and TNF- $\alpha$ were augmented in the diabetic $d b / d b$ mice compared with normal $\mathrm{m} / \mathrm{m}$ mice. These up-regulated proteins were markedly down-regulated by oligonol treatment, as reported previously (31). This indicates that the downregulation of TNF- $\alpha$ or oxidative stress-mediated JNK signaling affected the renal apoptotic response.

Therefore, we subsequently examined renal apoptosis-related protein expression in the kidney of $d b / d b$ mice with oligonol administration. Podocyte loss caused by detachment or apoptosis will lead to a decrease in the density of podocytes. Reduction of the podocyte density is an important determinant of progressive diabetic nephropathy and precedes the development of renal dysfunction and albuminuria in diabetic patients and animal models of diabetes mellitus (65). The marked increase in podocyte apoptosis observed during the early stage of diabetes 
(A)

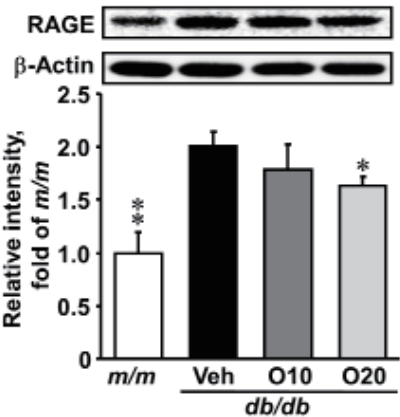

(D)

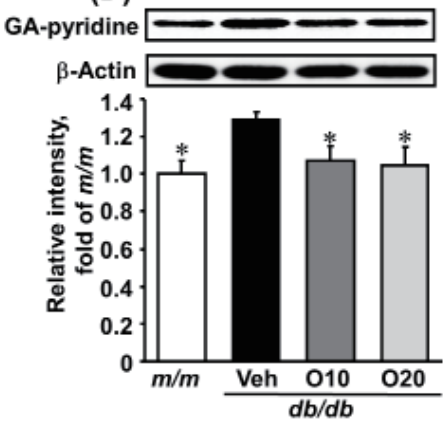

(B)
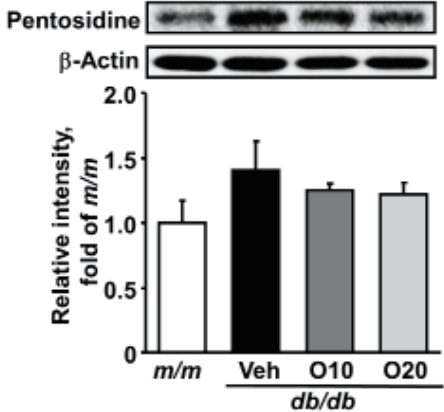

(E)

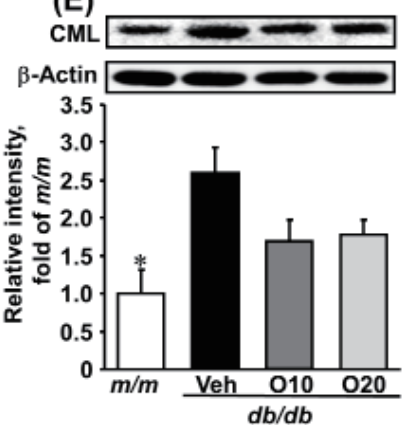

(C)

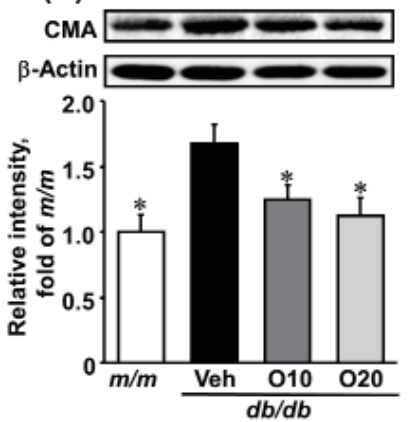

(F)

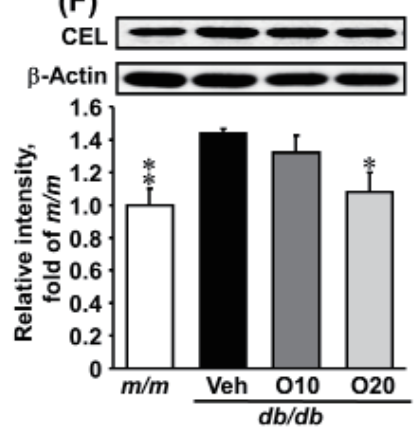

Figure 4. Renal RAGE (A), pentosidine (B), CMA (C), GA-pyridine (D), CML (E), and CEL (F) protein expressions. Values are mean \pm S.E.M. Significance: ${ }^{*} p<0.05,{ }^{* *} p<0.01 v s$. vehicle-treated $d b / d b$ group. $m / m$, vehicle-treated $m / m$ mice $(n$ $=6) ; d b / d b$-Veh, vehicle-treated $d b / d b$ mice $(n=10) ; d b / d b$-O10, oligonol $10 \mathrm{mg} / \mathrm{kg}$ body weight-treated $d b / d b \mathrm{mice}(n=10) ; d b /$ $d b$-O20, oligonol $20 \mathrm{mg} / \mathrm{kg}$ body weight-treated $d b / d b$ mice $(n=10)$. Ref. (31).

in $d b / d b$ mice is mediated to a large extent by the activation of NADPH oxidase and its contribution to the generation of ROS (65). Our results support the idea that the decrease in NADPH oxidase expression affected the proapoptotic protein expression. Oligonol administration led to a significant increase in Bcl-2 and survivin and reduction of Bax, cytochrome $c$, and caspase- 3 protein in the renal tissue of $d b / d b$ mice, as shown in a previously report (31). These data suggest that the attenuation of diabetic renal apoptosis is influenced by decreased NADPH oxidase-dependent oxidative stress and/or JNK-related signaling.

Under type 2 diabetes, the redox-sensitive intracellular signaling pathway is altered. In particular, one major intracellular target of hyperglycemia and oxidative stress is the transcription factor NF- $\mathrm{KB}$. NF$\kappa \mathrm{B}$ can be activated by a wide array of exogenous and endogenous stimuli, including hyperglycemia, elevated NEFA, ROS, TNF- $\alpha$, interleukin- $1 \beta$, other proinflammatory cytokines, AGE-binding RAGE, and $\mathrm{p} 38 \mathrm{MAPK}$. The activation of NF- $\mathrm{kB}$ induces the inflammation-related proteins COX-2 and iNOS, and the subsequent production of prostaglandin and nitric oxide (NO), respectively. NO reacts very rapidly with superoxide to form peroxynitrite and other NO-derived oxidants capable of damaging DNA and proteins (66). There is a vicious cycle involving NF- $\mathrm{KB}$, oxidative stress, and inflammation under the diabetic condition. Therefore, the inhibition of NF- $\mathrm{kB}$ transcription plays a central role in regulating the pathophysiology of diabetic complications. Elevated protein expressions of
NF-KBp65 and iNOS in the liver of $d b / d b$ mice were markedly down-regulated by oligonol administration (31). Oligonol administration could adjust inflammation through the inhibition of the NF- $\mathrm{kB}$ pathway.

\section{Conclusion}

Oligonol, which is now available commercially as a new dietary ingredient, is an optimized phenolic product derived from lychee fruit polyphenols containing catechin-type monomers and low-molecular-weight oligomers (21). Based on recent studies, there is accumulating evidence that oligonol can induce some physiological and biochemical alterations in vitro and in vivo, such as the induction of apoptosis in cancer cells (23), antioxidant and anti-inflammatory effects in mice (24), and beneficial subjective effects on the feeling of fatigue in young athletes (67). Moreover, the oral administration of oligonol improves the regulation of genes for adipokines in white adipose tissue of mice on administering a high-fat diet (26). The dietary feeding of proanthocyanidins, which comprise oligonol, has been reported to induce the significant attenuation of tissue fat levels, without changing the total body mass of animals compared with non-proanthocyanidin-fed animals (28). In this review, we summarize our recent work: oligonol was able to improve diabetic indices, prevent the development of diabetic renal disease, and preserve renal cells and the renal morphological structure via the attenuation of NADPH oxidase-induced oxidative stress, inhibition of AGE generation, and prevention 


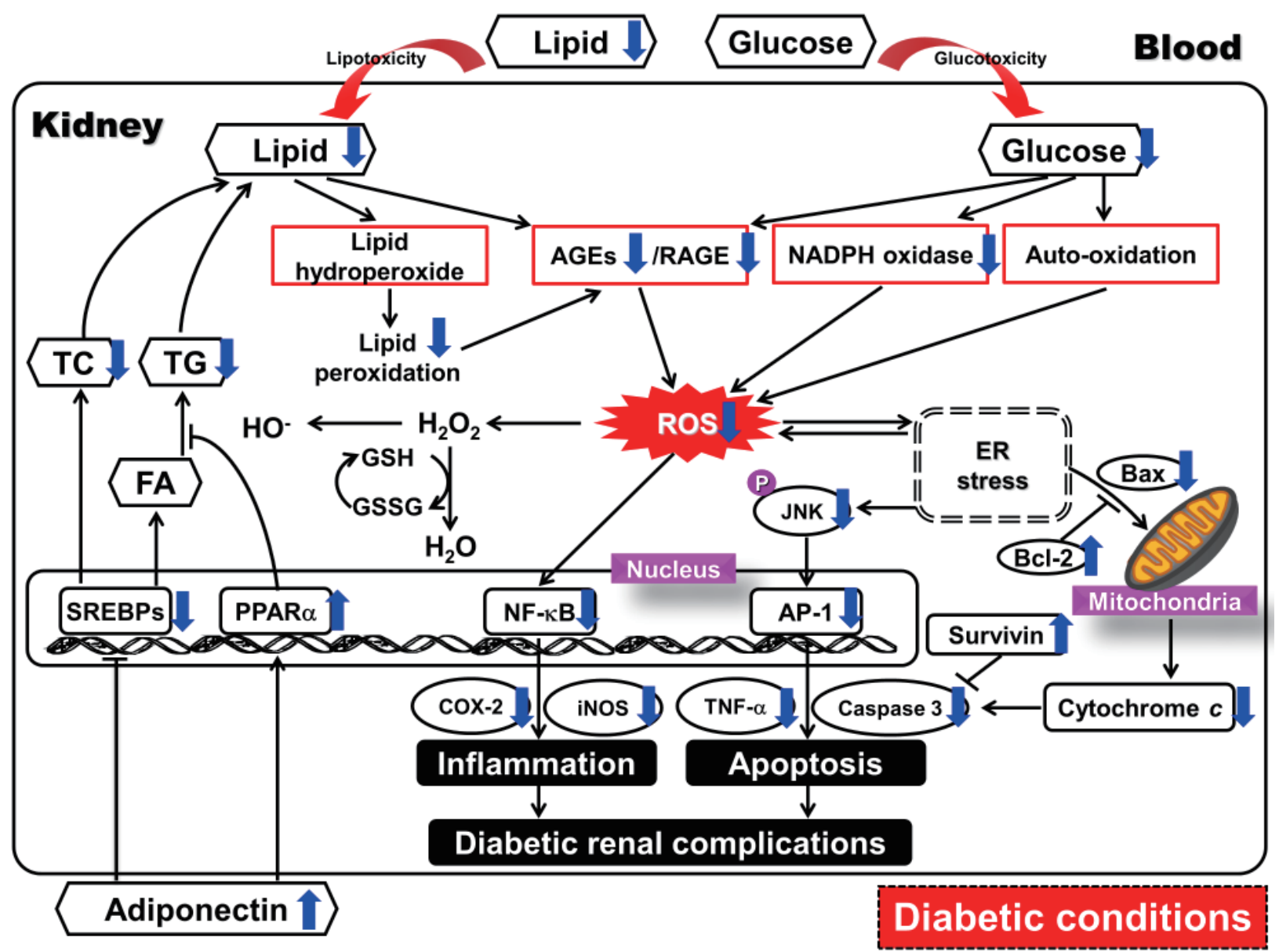

Figure 5. Predicted mechanism in renal tissues on administering oligonol against oxidative stress, AGE formation, and apoptosis. Oligonol attenuated glucose and lipid accumulation, the regulation of transcription factors for lipid metabolism, and subsequently decreased NADPH oxidase-derived ROS production in the kidney. Furthermore, oligonol ameliorated the values of AGE-related protein expressions (RAGE, CMA, GA-pyridinine, and CEL), anti-apoptotic protein expressions (Bcl-2 and survivin), and apoptotic protein expressions (JNK, p-JNK, AP-1, Bax, cytochrome $c$, and caspase-3 proteins).

of apoptosis-induced cell death in $d b / d b$ mice, being independent of changes in the body weight or serum glucose levels (Figure 5). Accordingly, oligonol may be a promising dietary supplement for the prevention or delaying of diabetic renal complications. With respect to the current research, more clinical studies are needed on the management of hyperglycemia and inflammation in both healthy subjects and metabolic syndrome patients and its pharmaceutical kinetics in order to develop therapeutic agents.

\section{References}

1. Srikanthan P, Hsueh W. Preventing heart failure in patients with diabetes. Med Clin North Am. 2004; 88:1237-1256.

2. Younossi ZM, Gramlich T, Matteoni CA, Boparai N, McCullough AJ. Nonalcoholic fatty liver disease in patients with type 2 diabetes. Clin Gastroenterol Hepatol. 2004; 2:262-265.

3. Chang-Chen KJ, Mullur R, Bernal-Mizrachi E. $\beta$-Cell failure as a complication of diabetes. Rev Endocr Metab Disord. 2008; 9:329-343.

4. Kanwar YS, Wada J, Sun L, Xie P, Wallner EI, Chen S,
Chugh S, Danesh FR. Diabetic nephropathy: Mechanisms of renal disease progression. Exp Biol Med (Maywood). 2008; 233:4-11.

5. Vander Jagt DL, Hassebrook RK, Hunsaker LA, Brown WM, Royer RE. Metabolism of the 2-oxoaldehyde methylglyoxal by aldose reductase and by glyoxalase-I: Roles for glutathione in both enzymes and implications for diabetic complications. Chem Biol Interact. 2001; 130-132:549-562.

6. Barnes PJ. Nuclear factor- $\kappa$ B. Int J Biochem Cell Biol. 1997; 29:867-870.

7. Yamamoto Y, Gaynor RB. Role of the NF- $\mathrm{kB}$ pathway in the pathogenesis of human disease states. Curr Mol Med. 2001; 1:287-296.

8. Zhang GL, Wang YH, Teng HL, Lin ZB. Effects of aminoguanidine on nitric oxide production induced by inflammatory cytokines and endotoxin in cultured rat hepatocytes. World J Gastroenterol. 2001; 7:331-334.

9. Maritim AC, Sanders RA, Watkins JB 3rd. Diabetes, oxidative stress, and antioxidants: A review. J Biochem Mol Toxicol. 2003; 17:24-38.

10. Rolo AP, Palmeira CM. Diabetes and mitochondrial function: Role of hyperglycemia and oxidative stress. Toxicol Appl Pharmacol. 2006; 212:167-178.

11. Nishikawa T, Araki E. Impact of mitochondrial ROS production in the pathogenesis of diabetes mellitus and 
its complications. Antioxid Redox Signal. 2007; 9:343353.

12. Gao L, Mann GE. Vascular NAD(P)H oxidase activation in diabetes: A double-edged sword in redox signaling. Cardiovasc Res. 2009; 82:9-20.

13. Winslow LC, Kroll DJ. Herbs as medicines. Arch Intern Med. 1998; 158:2192-2199.

14. Jones PJ, Varady KA. Are functional foods redefining nutritional requirements? Appl Physiol Nutr Metab. 2008; 33:118-123.

15. Nakayama M, Suzuki K, Toda M, Okubo S, Hara Y, Shimamura T. Inhibition of the infectivity of influenza virus by tea polyphenols. Antiviral Res. 1993; 21:289-299.

16. Hsieh TC, Wu JM. Differential effects on growth, cell cycle arrest, and induction of apoptosis by resveratrol in human prostate cancer cell lines. Exp Cell Res. 1999; 249:109-115.

17. Pal S, Choudhuri T, Chattopadhyay S, Bhattacharya A, Datta GK, Das T, Sa G. Mechanisms of curcumininduced apoptosis of Ehrlich's ascites carcinoma cells. Biochem Biophys Res Commun. 2001; 288:658-665.

18. Brat P, Georgé S, Bellamy A, Chaffaut LD, Scalbert A, Mennen L, Arnault N, Amiot MJ. Daily polyphenol intake in France from fruit and vegetables. J Nutr. 2006; 136:2368-2373.

19. Haslam E. Natural polyphenols (vegetable tannins) as drugs: Possible modes of action. J Nat Prod. 1996; 59:205-215.

20. Tanaka T, Yoshitake N, Zhao P, Matsuo Y, Kouno I, Nonaka G. Production of oligomeric proanthocyanidins by fragmentation of polymers. Jpn J Food Chem. 2007; 14:134-139.

21. Kitadate K, Homma K, Roberts A, Maeda T. Thirteenweek oral dose toxicity study of Oligonol containing oligomerized polyphenols extracted from lychee and green tea. Regul Toxicol Pharmacol. 2014; 68:140-146.

22. Fujii H, Nishioka H, Wakame K, Magnuson BA, Roberts A. Acute, subchronic and genotoxicity studies conducted with Oligonol, an oligomerized polyphenol formulated from lychee and green tea extracts. Food Chem Toxicol. 2008; 46:3553-3562.

23. Jo EH, Lee SJ, Ahn NS, Park JS, Hwang JW, Kim SH, Aruoma OI, Lee YS, Kang KS. Induction of apoptosis in MCF-7 and MDA-MB-231 breast cancer cells by Oligonol is mediated by Bcl-2 family regulation and MEK/ERK signaling. Eur J Cancer Prev. 2007; 16:342347.

24. Kundu JK, Chang EJ, Fujii H, Sun B, Surh YJ. Oligonol inhibits UVB-induced COX-2 expression in HR-1 hairless mouse skin - AP-1 and C/EBP as potential upstream targets. Photochem Photobiol. 2008; 84:399406.

25. Zhang XH, Yokoo H, Nishioka H, Fujii H, Matsuda $\mathrm{N}$, Hayashi T, Hattori Y. Beneficial effect of the oligomerized polyphenol oligonol on high glucoseinduced changes in eNOS phosphorylation and dephosphorylation in endothelial cells. Br J Pharmacol. 2010; 159:928-938.

26. Sakurai T, Nishioka H, Fujii H, Nakano N, Kizaki T, Radak Z, Izawa T, Haga S, Ohno H. Antioxidative effects of a new lychee fruit-derived polyphenol mixture, oligonol, converted into a low-molecular form in adipocytes. Biosci Biotechnol Biochem. 2008; 72:463476.

27. Ogasawara J, Kitadate K, Nishioka H, Fujii H, Sakurai
T, Kizaki T, Izawa T, Ishida H, Ohno H. Oligonol, a new lychee fruit-derived low-molecular form of polyphenol, enhances lipolysis in primary rat adipocytes through activation of the ERK1/2 pathway. Phytother Res. 2009; 23:1626-1633.

28. Mittal A, Elmets CA, Katiyar SK. Dietary feeding of proanthocyanidins from grape seeds prevents photocarcinogenesis in SKH-1 hairless mice: Relationship to decreased fat and lipid peroxidation. Carcinogenesis. 2003; 24:1379-1388.

29. Iseki K, Nakai S, Shinzato T, Nagura Y, Akiba T. Increasing gender difference in the incidence of chronic dialysis therapy in Japan. Ther Apher Dial. 2005; 9:407411.

30. Noh JS, Kim HY, Park CH, Fujii H, Yokozawa T. Hypolipidaemic and antioxidative effects of oligonol, a low-molecular-weight polyphenol derived from lychee fruit, on renal damage in type 2 diabetic mice. Br J Nutr. 2010; 104:1120-1128.

31. Park CH, Yokozawa T, Noh JS. Oligonol, a lowmolecular-weight polyphenol derived from lychee fruit, attenuates diabetes-induced renal damage through the advanced glycation end product-related pathway in $d b$ / $d b$ mice. J Nutr. 2014; 144:1150-1157.

32. Sharma K, McCue P, Dunn SR. Diabetic kidney disease in the $d b / d b$ mouse. Am J Physiol Renal Physiol. 2003; 284:F1138-F1144.

33. Rabe K, Lehrke M, Parhofer KG, Broedl UC. Adipokines and insulin resistance. Mol Med. 2008; 14:741-751.

34. Tobe K, Suzuki R, Aoyama M, Yamauchi T, Kamon J, Kubota N, Terauchi Y, Matsui J, Akanuma Y, Kimura S, Tanaka J, Abe M, Ohsumi J, Nagai R, Kadowaki T. Increased expression of the sterol regulatory elementbinding protein-1 gene in insulin receptor substrate- $2^{-/-}$ mouse liver. J Biol Chem. 2001; 276:38337-38340.

35. Wang Z, Jiang T, Li J, Proctor G, McManaman JL, Lucia S, Chua S, Levi M. Regulation of renal lipid metabolism, lipid accumulation, and glomerulosclerosis in $\mathrm{FVB}^{d b / d b}$ mice with type 2 diabetes. Diabetes. 2005; 54:2328-2335.

36. Ferré P. The biology of peroxisome proliferator-activated receptors: Relationship with lipid metabolism and insulin sensitivity. Diabetes. 2004; 53 (Suppl 1):S43-S50.

37. Park CW, Zhang Y, Zhang X, Wu J, Chen L, Cha DR, Su D, Hwang MT, Fan X, Davis L, Striker G, Zheng F, Breyer M, Guan Y. PPAR $\alpha$ agonist fenofibrate improves diabetic nephropathy in $d b / d b$ mice. Kidney Int. 2006; 69:1511-1517.

38. Evans JL, Goldfine ID, Maddux BA, Grodsky GM. Are oxidative stress-activated signaling pathways mediators of insulin resistance and $\beta$-cell dysfunction? Diabetes. 2003; 52:1-8.

39. Niki E, Yamamoto Y, Komuro E, Sato K. Membrane damage due to lipid oxidation. Am J Clin Nutr. 1991; 53 (1 Suppl):201S-205S.

40. Rietveld A, Wiseman S. Antioxidant effects of tea: Evidence from human clinical trials. J Nutr. 2003; 133:3285S-3292S.

41. Crespy V, Williamson G. A review of the health effects of green tea catechins in in vivo animal models. J Nutr. 2004; 134 (12 Suppl):3431S-3440S.

42. Leiherer A, Mündlein A, Drexel H. Phytochemicals and their impact on adipose tissue inflammation and diabetes. Vascul Pharmacol. 2013; 58:3-20.

43. Yamabe N, Yokozawa T, Oya T, Kim M. Therapeutic potential of (-)-epigallocatechin 3-O-gallate on renal 
damage in diabetic nephropathy model rats. J Pharmacol Exp Ther. 2006; 319:228-236.

44. Sedeek M, Callera G, Montezano A, Gutsol A, Heitz F, Szyndralewiez C, Page P, Kennedy CR, Burns KD, Touyz RM, Hébert RL. Critical role of Nox4-based NADPH oxidase in glucose-induced oxidative stress in the kidney: Implications in type 2 diabetic nephropathy. Am J Physiol Renal Physiol. 2010; 299:F1348-F1358.

45. Yan SD, Schmidt AM, Anderson GM, Zhang J, Brett J, Zou YS, Pinsky D, Stern D. Enhanced cellular oxidant stress by the interaction of advanced glycation end products with their receptors/binding proteins. J Biol Chem. 1994; 269:9889-9897.

46. Bahadoran Z, Mirmiran P, Azizi F. Dietary polyphenols as potential nutraceuticals in management of diabetes: A review. J Diabetes Metab Disord. 2013; 12:43.

47. Song J, Kwon O, Chen S, Daruwala R, Eck P, Park JB, Levine M. Flavonoid inhibition of sodium-dependent vitamin C transporter 1 (SVCT1) and glucose transporter isoform 2 (GLUT2), intestinal transporters for vitamin C and glucose. J Biol Chem. 2002; 277:15252-15260.

48. Johnston K, Sharp P, Clifford M, Morgan L. Dietary polyphenols decrease glucose uptake by human intestinal Caco-2 cells. FEBS Lett. 2005; 579:1653-1657.

49. Goh SY, Cooper ME. The role of advanced glycation end products in progression and complications of diabetes. $\mathrm{J}$ Clin Endocrinol Metab. 2008; 93:1143-1152.

50. Baynes JW, Thorpe SR. Role of oxidative stress in diabetic complications: A new perspective on an old paradigm. Diabetes. 1999; 48:1-9.

51. Ahmed N. Advanced glycation endproducts - role in pathology of diabetic complications. Diabetes Res Clin Pract. 2005; 67:3-21.

52. Monnier VM, Bautista O, Kenny D, Sell DR, Fogarty J, Dahms W, Cleary PA, Lachin J, Genuth S. Skin collagen glycation, glycoxidation, and crosslinking are lower in subjects with long-term intensive versus conventional therapy of type 1 diabetes: Relevance of glycated collagen products versus $\mathrm{HbA}_{1 \mathrm{c}}$ as markers of diabetic complications. DCCT Skin Collagen Ancillary Study Group. Diabetes Control and Complications Trial. Diabetes. 1999; 48:870-880.

53. Yan SD, Schmidt AM, Anderson GM, Zhang J, Brett J, Zou YS, Pinsky D, Stern D. Enhanced cellular oxidant stress by the interaction of advanced glycation end products with their receptors/binding proteins. J Biol Chem. 1994; 269:9889-9897.

54. Koito W, Araki T, Horiuchi S, Nagai R. Conventional antibody against $N^{e}$-(carboxymethyl)lysine (CML) shows cross-reaction to $N^{e}$-(carboxyethyl)lysine (CEL): Immunochemical quantification of CML with a specific antibody. J Biochem. 2004; 136:831-837.

55. Sell DR, Nagaraj RH, Grandhee SK, Odetti P, Lapolla A, Fogarty J, Monnier VM. Pentosidine: A molecular marker for the cumulative damage to proteins in diabetes, aging, and uremia. Diabetes Metab Rev. 1991; 7:239-251.

56. Lapolla A, Piarulli F, Sartore G, Ceriello A, Ragazzi E, Reitano R, Baccarin L, Laverda B, Fedele D. Advanced glycation end products and antioxidant status in type 2 diabetic patients with and without peripheral artery disease. Diabetes Care. 2007; 30:670-676.

57. Odani H, Iijima K, Nakata M, Miyata S, Kusunoki H, Yasuda Y, Hiki Y, Irie S, Maeda K, Fujimoto D. Identification of $N^{e}$-carboxymethylarginine, a new advanced glycation endproduct in serum proteins of diabetic patients: possibility of a new marker of aging and diabetes. Biochem Biophys Res Commun. 2001; 285:1232-1236.

58. Iijima K, Murata M, Takahara H, Irie S, Fujimoto D. Identification of $N^{e}$-carboxymethylarginine as a novel acid-labile advanced glycation end product in collagen. Biochem J. 2000; 347:23-27.

59. Glomb MA, Monnier VM. Mechanism of protein modification by glyoxal and glycolaldehyde, reactive intermediates of the Maillard reaction. J Biol Chem. 1995; 270:10017-10026.

60. Anderson MM, Requena JR, Crowley JR, Thorpe SR, Heinecke JW. The myeloperoxidase system of human phagocytes generates $N^{e}$-(carboxymethyl)lysine on proteins: a mechanism for producing advanced glycation end products at sites of inflammation. J Clin Invest. 1999; 104:103-113.

61. Nagai R, Hayashi CM, Xia L, Takeya M, Horiuchi S. Identification in human atherosclerotic lesions of GApyridine, a novel structure derived from glycolaldehydemodified proteins. J Biol Chem. 2002; 277:48905-48912.

62. Wada T, Penninger JM. Mitogen-activated protein kinases in apoptosis regulation. Oncogene. 2004; 23:2838-2849.

63. Liu J, Minemoto Y, Lin A. c-Jun N-terminal protein kinase 1 (JNK1), but not JNK2, is essential for tumor necrosis factor alpha-induced c-Jun kinase activation and apoptosis. Mol Cell Biol. 2004; 24:10844-10856.

64. Widenmaier SB, Ao Z, Kim SJ, Warnock G, Mclntosh CH. Suppression of p38 MAPK and JNK via Aktmediated inhibition of apoptosis signal-regulating kinase 1 constitutes a core component of the $\beta$-cell pro-survival effects of glucose-dependent insulinotropic polypeptide. J Biol Chem. 2009; 284:30372-30382.

65. Susztak K, Raff AC, Schiffer M, Böttinger EP. Glucoseinduced reactive oxygen species cause apoptosis of podocytes and podocyte depletion at the onset of diabetic nephropathy. Diabetes. 2006; 55:225-233.

66. Surh YJ, Chun KS, Cha HH, Han SS, Keum YS, Park KK, Lee SS. Molecular mechanisms underlying chemopreventive activities of anti-inflammatory phytochemicals: down-regulation of COX-2 and iNOS through suppression of NF- $\kappa B$ activation. Mutat Res. 2001; 480-481:243-268.

67. Ohno H, Sakurai T, Hisajima T, Abe S, Kizaki T, Ogasawara J, Ishibashi Y, Imaizumi K, Takemasa T, Haga S, Kitadate K, Nishioka H, Fujii H. The supplementation of Oligonol, the new lychee fruit-derived polyphenol converting into a low-molecular form, has a positive effect on fatigue during regular track-and-field training in young athletes. Adv Exerc Sport Physiol. 2008; 13:9399.

(Received January 22, 2015; Revised January 30, 2015; Accepted February 9, 2015) 